\title{
Long-term efficacy of mycophenolate mofetil in myelin oligodendrocyte glycoprotein antibody-associated disorders
}

\author{
A prospective study
}

Shengde Li, MD, Haitao Ren, BS, Yan Xu, MD, PhD, Tao Xu, MD, Yao Zhang, MD, Hexiang Yin, MD, Weihua Zhang, MD, Jiuwei Li, MD, Xiaotun Ren, MD, Fang Fang, MD, Wenhan Li, MD, Yicheng Zhu, MD, Bin Peng, MD, Jing Wang, MD, Yong Zhong, MD, and Liying Cui, MD

Neurol Neuroimmunol Neuroinflamm 2020;7:e705. doi:10.1212/NXI.0000000000000705

\section{Abstract}

\section{Objective}

To investigate whether the use of mycophenolate mofetil (MMF) could reduce the relapse risk in patients with myelin oligodendrocyte glycoprotein (MOG)-immunoglobulin G (IgG)-associated disorders (MOGADs).

\section{Methods}

This prospective observational cohort study included patients with MOGAD at Peking Union Medical College Hospital between January 1, 2017, and April 30, 2019. The patients were divided into 2 groups: those with $(\mathrm{MMF}+)$ or without $(\mathrm{MMF}-) \mathrm{MMF}$ therapy. The primary outcome was relapse at follow-up. We used Cox proportional hazards models to calculate hazard ratios (HRs) for relapse.

\section{Results}

Seventy-nine patients were included in our MOG cohort. Fifty $(63.3 \%)$ were adults at index date, and 47 (59.5\%) were women. Fifty-four (68.4\%) were in the MMF+ group, and 25 (31.6\%) were in the MMF- group. Clinical and demographic factors, MOG-IgG titer, and follow-up time (median, 472.5 days for $\mathrm{MMF}+, 261.0$ days for MMF-) were comparable between the groups. Relapse rates were $7.4 \%(4 / 54)$ in the MMF+ group and $44.0 \%(11 / 25)$ in the MMF- group. Of all potential confounders, only the use of MMF was associated with reduced risk of relapse. The HR for relapse among patients in the $\mathrm{MMF}+$ group was 0.14 (95\% CI, 0.05-0.45) and was 0.08 (95\% CI, 0.02-0.28) in a model adjusted for age, sex, disease course, and MOG-IgG titer. MMF therapy also remained associated with a reduced relapse risk in sensitivity analyses. Only one patient (1.9\%) discontinued MMF therapy because of adverse effect.

\section{Conclusions}

These findings provide a clinical evidence that MMF immunosuppression therapy may prevent relapse in patients with MOGAD.

\section{Classification of evidence}

This study provides class IV evidence that for patients with MOGAD, MMF reduces relapse risk.

\author{
Correspondence \\ Dr. Xu \\ xuyanpumch@hotmail.com
}

MORE ONLINE

$\rightarrow$ Class of Evidence

Criteria for rating therapeutic and diagnostic studies

NPub.org/coe 


\section{Glossary}

ADEM = acute disseminated encephalomyelitis; ARR = annualized relapse rate; $\mathbf{A Z A}=$ azathioprine; $\mathbf{E D S S}=$ expanded disability status scale; HR = hazard ratio; IgG = immunoglobulin G; IIFT = indirect immunofluorescence test; IQR = interquartile range; $\mathbf{M M F}=$ mycophenolate mofetil; $\mathbf{M O G}=$ myelin oligodendrocyte glycoprotein; MOGAD = MOG-IgGassociated disorders; NMOSD $=$ neuromyelitis optica spectrum disorder.

Myelin oligodendrocyte glycoprotein (MOG), which is expressed on the surface of myelin sheaths in the CNS, is targeted by antibodies (MOG-immunoglobulin $\mathrm{G}[\mathrm{IgG}]$ ) in inflammatory demyelinating disorders, ${ }^{1,2}$ including MS, acute disseminated encephalomyelitis (ADEM), neuromyelitis optica spectrum disorder (NMOSD), and optic neuritis, although positive rate is very low in MS. ${ }^{1,3,4}$ However, clinical, radiologic, CSF, and prognostic features in patients with seropositive MOG-IgG are distinct from those in patients with seropositive AQP4-IgG NMOSD, seronegative NMOSD, or MS. ${ }^{5-7}$ With the aid of serum MOG-IgG detected by transfected cell-based assay, seropositive MOG-IgG demyelinating disorders are now classified as a separate disease entity with distinct diagnostic criteria. ${ }^{2,8}$

Patients with MOG-IgG-associated disorders (MOGADs) exhibit a predominantly relapsing and often severe disease course from $36 \%$ relapse rate in a median 16 -month to $80 \%$ in a mean 75 -month follow-up period. ${ }^{9,10}$ Many patients do not completely recover from the onset attack, with $47 \%$ of patients having permanent disability. ${ }^{10}$ Although the longterm immunosuppression therapy seemed to reduce relapse risk, there is a lack of prospective data and large sample studies. ${ }^{9,10}$ In view of the heterogeneity of the treatments given, there is still a need to define an optimal strategy, especially considering that the relapse rate of treated patients is still too high. ${ }^{9}$ Therefore, prophylactic long-term treatments remain insufficiently effective, with little evidence for the ability of long-term therapy to reduce relapse risk among patients with MOGAD. Here, we conducted a prospective observational cohort study of patients with MOGAD to determine the association of relapse risk and the use of mycophenolate mofetil (MMF) because the efficiency and safety of MMF has been confirmed in patients with NMOSD. ${ }^{11,12}$

\section{Methods}

\section{Study design and patients}

Patients enrolled in the Peking Union Medical College hospital MSNMOBase database ${ }^{12}$ were followed up prospectively in the period of 2017-2019, after undergoing a MOG-IgG laboratory test (figure 1). Participating patients were included into the MOG cohort when they met all the following criteria: (1) clinical presentation of ADEM, optic neuritis (including chronic relapsing inflammatory optic neuropathy), transverse myelitis, and/or brain or brainstem syndrome compatible with demyelination; (2) serum positive for MOG-IgG by a fixed cellbased indirect immunofluorescence test (IIFT); (3) exclusion of alternative diagnoses based on clinical features, serum and CSF results, and imaging findings; and (4) diagnosis of MOGIgG-associated disorder confirmed by a neurologist.

The Institutional Review Board of Peking Union Medical College Hospital approved this study and confirmed that it did not meet the definition of human subjects research under the common law because deidentified data were analyzed, which waived the need for informed consent.

\section{Procedures}

Patient data including sociodemographic information, clinical events, medical history, Expanded Disability Status Scale (EDSS) score, prescriptions, imaging, and results of serum and CSF tests were prospectively collected at the time of MSNMOBase enrollment. If a patient was suspected of having a MOGAD by a neurologist, serum MOG-IgG was detected by IIFT (FA 1156-1010-50; Euroimmun AG, Lüebeck, Germany) using full-length human MOG transfected into EUROIMMUN 90 cells. ${ }^{13}$ Owing to the recommended semiquantitative evaluation for the IIFT methodology, MOG-IgG titers were determined according to their fluorescence of the different sample dilutions.

On January 1, 2017, the board of neurologists (leader), ophthalmologists, and pediatricians on MOGAD was established. Participating patients in the MOG cohort received either MMF or non-MMF on to the decisions of the patient or their guardians after a complete and thorough discussion with the board. According to the purpose of this study, patients who rejected MMF but chose azathioprine (AZA) as an alternative were excluded. Thus, the participating patients in the MOG cohort were divided into 2 therapeutic groups, those with and without MMF therapy, i.e., $\mathrm{MMF}+$ and MMF-, respectively (figure 1). Besides, all patients in the MOG cohort were given standard of care (see below). The index date (i.e., start of the follow-up) was defined as the date when the patient was diagnosed with an MOGAD. We regarded the onset prior and closest to the index date as the "index onset."

We did clinic follow-up every 6 months after index date. Information was collected at each time on relapse, EDSS, and results of serum tests. Images of the brain and spinal cord were scanned annually. Adverse effects were also monitored regularly. All available information gathered from assessments was reviewed by the neurologist. The endpoint of a follow-up in our analysis was on April 30, 2019. 


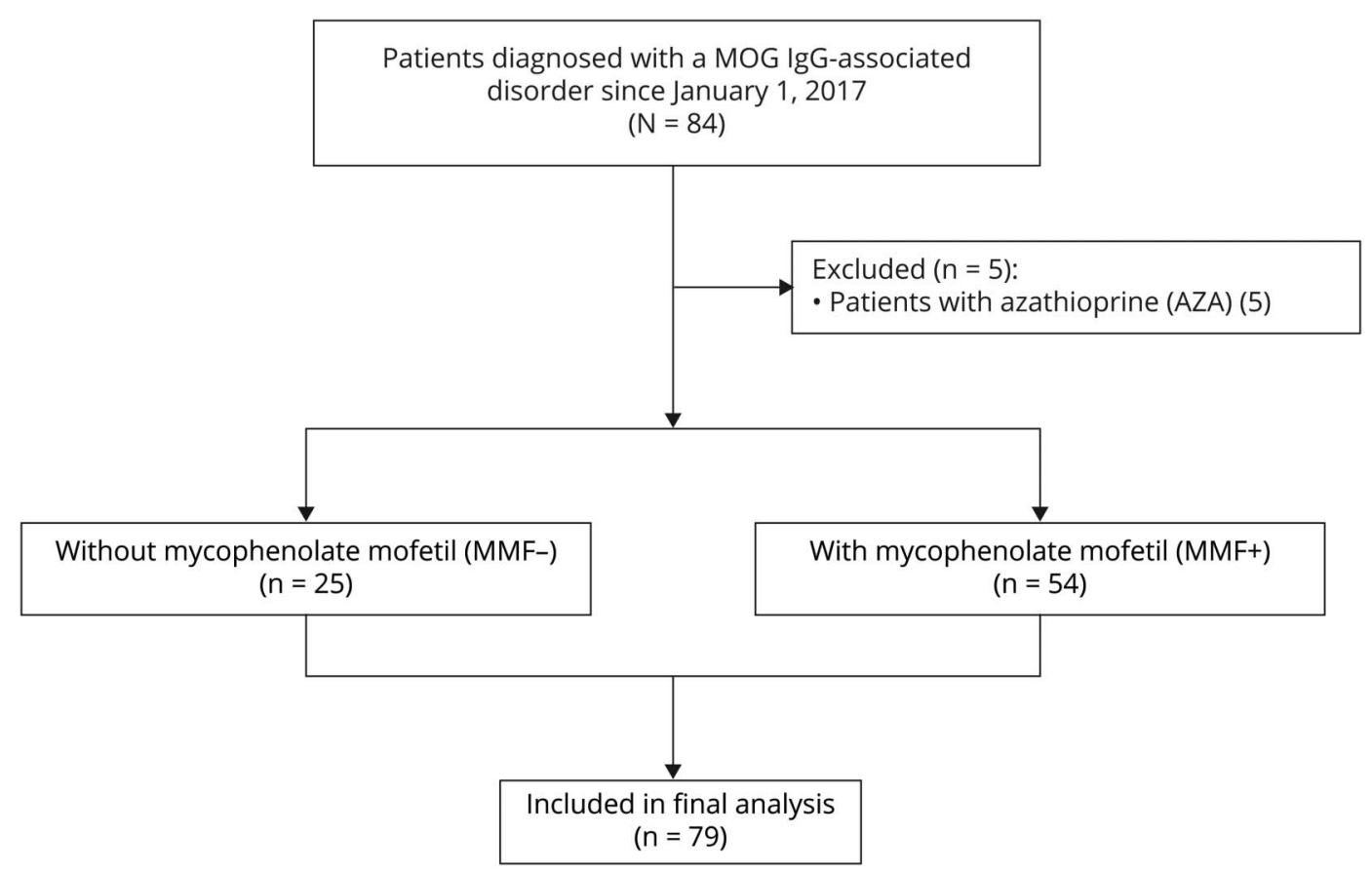

$\mathrm{AZA}=$ azathioprine; $\mathrm{MMF}=$ mycophenolate mofetil; MOG-IgG = myelin oligodendrocyte glycoprotein immunoglobulin G .

\section{Assessment of relapse}

The primary outcome was relapse, which was defined as a neurologic disturbance for at least 24 hours in the absence of other identifiable causes such as fever or infection, occurring more than 1 month after index onset and confirmed by a neurologist. The definition of relapse was based on the diagnostic criteria for MS and NMOSD and clinical judgment. ${ }^{14,15}$

\section{Standard of care}

Standard of care was defined as relatively fixed therapy in the acute or remission stage of the index onset. Standard of care included IV high-dose methylprednisolone, IV immunoglobulin, or a combination thereof in the acute phase, followed by tapering of oral prednisone in the remission stage (table e-1, links.lww.com/NXI/A223). Patients in the MMF+ and $\mathrm{MMF}$ - groups received the same tapering strategy of oral prednisone in the remission stage.

\section{MMF therapy}

MMF therapy was defined as the administration of MMF after the index date and lasting more than 14 days continuously. For adults, standard MMF therapy was $0.75 \mathrm{~g}$ twice per day ( $1.5 \mathrm{~g}$ per day). For children (<14 years), standard MMF therapy was calculated and adjusted by body surface area $\left(600 \mathrm{mg}\right.$ per $\left.\mathrm{m}^{2}\right)$ twice per day (fixed to $1.5 \mathrm{~g}$ per day if the maximum dose calculated by body surface area exceeded $1.5 \mathrm{~g}$ per day).

\section{Potential confounders}

Children were considered $<14$ years of age, and adults were considered $\geq 14$ years of age. MOG-IgG titers of $\geq 1: 100$ and
$<1: 100$ were defined as high and low, respectively. Prodromes were divided into 3 groups: none, preceding infection/vaccination, or other (e.g., fatigue and pregnancy). According to the symptoms and neurologic examination, onset attacks were classed as pure optic neuritis, pure cerebrum involvement, pure spinal involvement, or other (e.g., brainstem syndrome; table e-1, links.lww.com/NXI/A223). Disease course at index onset was divided into 2 subgroups: first (only one attack before index date) or nonfirst onset ( $\geq 2$ attacks before index date). The annualized relapse rate (ARR) before the index date was calculated by dividing the number of relapses by time in years. ARR was classified into 3 levels: $0,<3.0$, or $\geq 3.0$ (table e-1, links.lww.com/NXI/ A223).

\section{Sample size}

The primary analysis was performed using the Cox proportional hazards model to assess the efficacy of MMF therapy on relapse as the outcome measure. Hence, power calculation described by Rosner et al. and Freedman et al. was used. $^{16,17}$

Based on the studies by Huh et al. and Jarius et al., ${ }^{9,11}$ the relapse rates assumed in the $\mathrm{MMF}+$ group and $\mathrm{MMF}$ - group were $24 \%$ and $60 \%$, respectively. By considering the size ratio of the MMF+ to MMF- groups as 2 to 1 , this study assumed a sample size of 42 and 21 in the MMF+ group and MMFgroup, respectively. Then, we further assumed a postulated hazard ratio (HR) of 0.3 and a type I error rate of 0.05 ; this study had more than $90 \%$ power to detect a HR of 0.3 or lower. 


\section{Statistical analysis}

Continuous variables with non-normal distributions were presented as median and interquartile range (IQR), and categorical variables were presented as frequencies and percentages. Independent categorical and continuous variables with non-normal distributions were compared between the MMF+ and MMF- groups with $\chi^{2}$ and Mann-Whitney U tests, respectively. Continuous variables with normal distributions were compared with $t$ tests.

The Cox proportional hazards model was performed to assess the association between the prescriptions of MMF therapy and relapse rate. Confounders were evaluated by the change in estimate approach. ${ }^{18}$

We also assessed whether the association between MMF therapy and relapse differed between the following subgroups: children vs adults at index date, men vs women, high vs low MOG-IgG titer, prodrome type, onset type, time from first onset to index date, and first vs nonfirst onset disease course. Stratified Cox proportional hazards regressions were conducted for subgroup analysis. All statistical tests were twosided, with a significance level of $p<0.05$. Statistical analyses were conducted using SPSS version 26.0 (IBM).

\section{Data availability}

The data that support the findings of this study are available from the corresponding author on reasonable request.

\section{Results}

\section{Patient characteristics}

Seventy-nine patients from MSNMOBase were enrolled (figure 1). The baseline characteristics of the overall cohort, $\mathrm{MMF}+$ group, and MMF- group are presented in table 1 . Median age on index date was 19.0 years (IQR, 10.0-30.0 years), and 47 patients (59.5\%) were women. Patients in the MMF+ group were slightly older than those in the MMFgroup, whereas other demographic characteristics, clinical features, MOG-IgG titer, and follow-up times were comparable between groups (table 1). Most patients with nonfirst onset disease course received heterogenous and irregular prednisone therapy before index date $(100.0 \%$ in the MMF- group and $97.6 \%$ in the MMF+ group, $p=1.000)$, but only 3 patients had cyclophosphamide/AZA therapy ( 1 in the MMF- group and 2 in the MMF+ group, $p=1.000$ ). The previous therapies before index date were also comparable between the MMF+ and MMF- groups among all patients (data not shown).

After index date, 25 patients (100.0\%) in the MMF- group and $47(87.0 \%)$ in the MMF+ group received formulary standard tapering prednisone therapy (table 1). While in the MMF+ group, 1 patient (1.9\%) modified prednisone for suspected new lesion on brain MRI, 2 (3.7\%) stopped taking prednisone, and the other 4 patients $(7.4 \%)$ did not receive prednisone therapy. The prednisone therapy and its tapering time were comparable between 2 groups (table 1). The antibody's rates of negative transformation, persistent seropositivity, and undetermined status were $24.0 \%, 20.0 \%$, and $56.0 \%$ in the MMF- group, and $16.7 \%, 53.7 \%$, and $29.6 \%$ in the MMF+ group $(p=0.017)$. The mean intervals of negative transformation were 230.8 days in the MMF- group and 196.8 days in the MMF+ group $(p=0.733)$.

\section{Overall outcomes}

The relapse rates in the MMF- and MMF+ groups were $44.0 \%(11 / 25)$ and $7.4 \%(4 / 54)$, respectively. Median followup times for the MMF- and MMF+ groups were 261.0 and 472.5 days, respectively. The time from index date to relapse in the MMF- group (mean, 118.5 days) was similar to that in the MMF+ group (mean, 114.3 days) (table 1). Most relapse events in the MMF- group (81.8\%) and the MMF+ group (75.0\%) occurred within the first 200 days after the index date. For the MMF+ group, the median delay from the index date to receiving therapy was 21 days and delay times were comparable between relapse (median, 15.5 days) and nonrelapse (median, 22.5 days) groups $(p=0.427)$. One $(1.9 \%)$ patient in the MMF+ group discontinued MMF because of adverse effects (decreased neutrophilia count: $0.89^{*} 10^{9} / \mathrm{L}$ ). The numbers needed to treat were 2.7 .

\section{Predictors of relapse}

The Kaplan-Meier curves of survival free of relapse are shown in figure 2. The unadjusted Cox model indicates that MMF therapy markedly reduced the likelihood of relapse $(\mathrm{HR}=0.14$, 95\% CI, 0.05 to $0.45, p=0.001$; table 2 ). This association remained significant after adjusting for age type (i.e., children vs adults) at index date, sex, disease course, and initial level of MOG-IgG titer (HR = 0.08, 95\% CI, 0.02-0.28, $p<0.001)$.

Age type at first onset, age type at index date, sex, prodrome to first onset, first onset type, disease course, ARR, and time from first onset to the index date were not associated with relapse, as determined by the log-rank tests (tables e-2, links.lww. com/NXI/A223).

Of 79 patients, including 2 with missing data, 29 (37.7\%) had a low MOG-IgG titer and 48 (62.3\%) had a high MOG-IgG titer. Compared with a low titer, a high titer was not associated with relapse, as determined by a log-rank test. Demographic characteristics, clinical factors, and testing time were comparable between patients with low vs high titers, as was treatment types in the acute phase (table e-3, links.lww.com/NXI/ A223). In the multivariable Cox regression model shown in table 2, the HR for relapse in patients with a high titer compared with those with a low titer was 2.05 (95\% CI, 0.54-7.79, $p=0.291$ ).

\section{Subgroup analyses}

The results of subgroup analyses are presented in figure 3 . The reduction in relapse rate with MMF was consistent across all major subgroups. There were no significant interactions for any of the subgroups, although the power to 
Table 1 Clinical and serologic characteristics of the patients with MOG-IgG-associated disorders

\begin{tabular}{|c|c|c|c|c|}
\hline \multirow[b]{2}{*}{ Characteristic } & \multicolumn{3}{|l|}{ Median (IQR) } & \multirow[b]{2}{*}{$p$ Value } \\
\hline & Total & MMF- & MMF+ & \\
\hline Patients, n (\%) & 79 & $25(31.6)$ & $54(68.4)$ & NA \\
\hline Age at first onset, $y$ & $15.0(7.0-27.0)$ & $10.0(6.0-24.0)$ & $18.5(7.8-32.0)$ & 0.023 \\
\hline Adults at first onset, $\mathrm{n}(\%)$ & $44(55.7)$ & $11(44.0)$ & $33(61.1)$ & 0.154 \\
\hline Age at index date, $y$ & $19.0(10.0-30.0)$ & $11.0(6.5-25.5)$ & $23.0(10.0-33.0)$ & 0.004 \\
\hline Adults at index date, $\mathrm{n}(\%)$ & $50(63.3)$ & $12(48.0)$ & $38(70.4)$ & 0.055 \\
\hline Female, n (\%) & $47(59.5)$ & $16(64.0)$ & $31(57.4)$ & 0.579 \\
\hline Prodrome to first onset, $\mathrm{n}(\%)$ & & & & 0.371 \\
\hline None & $21(26.6)$ & $5(20.0)$ & $16(29.6)$ & \\
\hline Preceding infection/vaccination & $48(60.8)$ & $18(72.0)$ & $30(55.6)$ & \\
\hline Other $^{a}$ & $10(12.7)$ & $2(8.0)$ & $8(14.8)$ & \\
\hline First onset type, n (\%) & & & & 0.951 \\
\hline Pure optic neuritis & $28(35.4)$ & $9(36.0)$ & $19(35.2)$ & \\
\hline Pure cerebral involvement & $24(30.4)$ & $8(32.0)$ & $16(29.6)$ & \\
\hline Pure spinal involvement & $5(6.3)$ & $1(4.0)$ & $4(7.4)$ & \\
\hline Other $^{b}$ & $22(27.8)$ & $7(28.0)$ & $15(27.8)$ & \\
\hline First onset disease course, $n(\%)^{c}$ & $22(27.8)$ & $9(36.0)$ & $13(24.1)$ & 0.271 \\
\hline ARR before index date & $1.0(0-3.5)$ & $1.0(0-4.8)$ & $1.1(0.1-2.4)$ & 0.721 \\
\hline Level of ARR before index date, $n(\%)^{d}$ & & & & 0.139 \\
\hline 0 & $22(27.8)$ & $9(36.0)$ & $13(24.1)$ & \\
\hline$<3.0$ & $35(44.3)$ & $7(28.0)$ & $28(51.9)$ & \\
\hline$\geq 3.0$ & $22(27.8)$ & $9(36.0)$ & $13(24.1)$ & \\
\hline Initial MOG-IgG titer, n(\%) & & & & 0.636 \\
\hline 1:10 & $6(7.8)$ & $3(12.5)$ & $3(5.7)$ & \\
\hline $1: 32$ & $23(29.9)$ & $6(25.0)$ & $17(32.1)$ & \\
\hline 1:100 & $32(41.6)$ & $11(45.8)$ & 21 (39.6) & \\
\hline $1: 320$ & $16(20.8)$ & $4(16.7)$ & $12(22.6)$ & \\
\hline $\begin{array}{l}\text { Long-term standard } \\
\text { prednisone, } \mathrm{n}(\%)^{f}\end{array}$ & $72(91.1)$ & $25(100.0)$ & $47(87.0)$ & 0.091 \\
\hline $\begin{array}{l}\text { Time of standard tapering } \\
\text { prednisone, } n(\%)^{\mathrm{g}}\end{array}$ & & & & 0.143 \\
\hline$<3 \mathrm{mo}$ & $14(19.4)$ & $6(24.0)$ & $8(17.0)$ & \\
\hline 3-6 mo & $4(5.6)$ & $3(12.0)$ & $1(2.1)$ & \\
\hline$\geq 6 \mathrm{mo}$ & $54(75.0)$ & $16(64.0)$ & $38(80.9)$ & \\
\hline $\begin{array}{l}\text { Time from first onset to } \\
\text { index date, } d\end{array}$ & $278.0(87.0-1,306.0)$ & $153.0(85.0-793.0)$ & $456.5(91.5-1,490.8)$ & 0.155 \\
\hline $\begin{array}{l}\text { Time from index onset to } \\
\text { index date, } d\end{array}$ & $48.0(21.0-127.0)$ & $65.0(34.0-125.0)$ & $43.0(20.5-128.3)$ & 0.282 \\
\hline $\begin{array}{l}\text { Time from index date to relapse, } \\
\text { d, mean (SD) })^{\mathrm{h}}\end{array}$ & $117.3(113.4)$ & $118.5(123.9)$ & $114.3(94.0)$ & 0.952 \\
\hline EDSS score at last follow-up & $0(0-1)$ & $0(0-1)$ & $0(0-1)$ & 0.872 \\
\hline
\end{tabular}


Table 1 Clinical and serologic characteristics of the patients with MOG-IgG-associated disorders (continued)

\begin{tabular}{|c|c|c|c|c|}
\hline \multirow[b]{2}{*}{ Characteristic } & \multicolumn{3}{|l|}{ Median (IQR) } & \multirow[b]{2}{*}{$p$ Value } \\
\hline & Total & MMF- & MMF+ & \\
\hline EDSS score >1, $n(\%)^{i}$ & $7(8.9)$ & $1(4.0)$ & $6(11.1)$ & 0.422 \\
\hline Duration of follow-up, $d$ & $400.0(216.0-706.0)$ & $261.0(97.0-660.0)$ & 472.5 (271.3-709.0) & 0.159 \\
\hline \multicolumn{5}{|c|}{$\begin{array}{l}\text { Abbreviations: ARR = annualized relapse rate; EDSS = Expanded Disability Status Scale; IQR = interquartile range; MMF = mycophenolate mofetil; MOG = } \\
\text { myelin oligodendrocyte glycoprotein; } N A=\text { not applicable. } \\
\text { a Other includes } 3 \text { patients who were pregnant/lactating and } 7 \text { with fatigue/poor sleep/tension. } \\
\text { b Other includes } 9 \text { with cerebellum/brain stem involvement, } 4 \text { with optic neuritis and cerebrum involvement, } 3 \text { with myelitis and cerebrum involvement, } 2 \\
\text { with optic neuritis and myelitis, } 2 \text { with cerebellum/brain stem and cerebrum involvement, and } 2 \text { with meningitis. } \\
\text { c Patients with only one attack before index date. } \\
\text { d } 0 \text { : patients with } 1 \text { attack before the index date; }<3.0 \text { : patients with } \geq 2 \text { attacks before the index date and ARR <3.0; } \geq 3.0 \text { : patients with } \geq 2 \text { attacks before the } \\
\text { index date and ARR } \geq 3.0 \text {. } \\
\text { e Two missing datapoints. } \\
\text { f Patients without prednisone (4) or without standard prednisone (3) were regarded as "without long-term standard prednisone," } p \text { value for the Fisher test. } \\
\text { g Seventy-two patients with standard tapering prednisone were analyzed. Details of tapering regimen were shown in table e- } 1 \text {, links. Iww.com/NXI/A223. } \\
\text { h } t \text { test. }\end{array}$} \\
\hline
\end{tabular}

detect significant interactions might have been limited by the number of patients. Although not statistically significant, MMF tended to be more effective in adults at index date and in patients who had a first onset with preceding infection/ vaccination, pure optic neuritis at first onset, or a high MOG-IgG titer. The association between MMF therapy and relapse did not vary by sex or time from the first onset to index date.

\section{Sensitivity analyses}

Two patients had the index onset under the months' therapy of AZA and continued AZA after index onset, which might affect the efficacy of MMF because both were in the MMF+ group. Thus, we performed a log-rank test and Cox regression analysis excluding both patients. Sensitivity analysis including

Figure 2 Kaplan-Meier curves showing the probability of survival free of relapse in patients with an MOGIgG-associated disorder

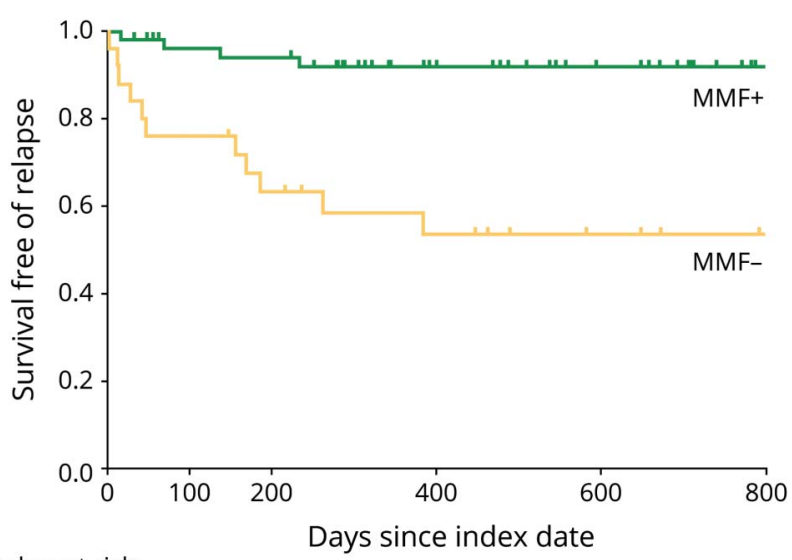

Number at risk:

MMF+ $54 \quad 46 \quad 45$

MMF- $25 \quad 19 \quad 15$

29

20

11

7

7

Log-rank test: $p<0.001$. Tick marks indicate censored patients. MMF = mycophenolate mofetil; MOG = myelin oligodendrocyte glycoprotein.
77 patients showed that MMF markedly reduced the relapse risk $(\mathrm{HR}=0.11,95 \% \mathrm{CI}, 0.03-0.39, p=0.001)$. In addition, to exclude the bias of nonstandard prednisone therapy, Cox regression analysis were conducted in 72 patients with standard tapering prednisone therapy (25 in the MMF- and 47 in the MMF+ group). Sensitivity analysis showed that MMF still predicted a lower relapse risk $(\mathrm{HR}=0.17,95 \% \mathrm{CI}, 0.05-0.52$, $p=0.002)$. The HR was still lower in the MMF+ group $(\mathrm{HR}=0.10,95 \% \mathrm{CI}, 0.03-0.33, p<0.001)$, adjusted for age type at index date, sex, disease course, and level of initial MOG-IgG titer.

\section{Discussion}

In this prospective observational cohort study including patients with MOGAD, we found that long-term MMF therapy reduced the risk of relapse by $86.0 \%$ with a median follow-up time of 400.0 days compared with treatment without MMF. Adverse effects were rare and detectable via regular monitoring. Unlike the relatively standard therapeutic regimen in patients with NMOSD, ${ }^{19}$ studies of long-term treatments for MOGAD have evaluated AZA, cyclophosphamide, methotrexate, interferon-beta, rituximab, mitoxantrone, ciclosporin, and tacrolimus and have reported varied or controversial outcomes for small numbers of patients, thus providing little evidence of therapy efficacy. ${ }^{7,9,10,20}$ For example, Ramanathan et al. ${ }^{21}$ reported that patients with MOGAD were highly responsive to steroids and also steroid-dependent. MMF tended to reduce relapse risk, but only with concurrent use of steroids. In addition, a study by Zhou et al. $^{22}$ showed that immunosuppression therapy was effective in reducing relapse but was limited to heterogenous therapeutic regimens and by a small sample size (23 patients). In addition, previous studies on reducing the relapse risk were all limited to retrospective analysis. As the optimal long-term therapy remains inconclusive, ${ }^{22,23}$ our prospective study suggests a new approach to effectively prevent relapse. 
Table 2 Cox regression models for MMF therapy and relapse in patients with MOG-IgG-associated disorders

\begin{tabular}{|c|c|c|c|c|c|}
\hline \multirow[b]{2}{*}{ Therapy } & \multirow[b]{2}{*}{ Events, n (\%) } & \multicolumn{2}{|l|}{ Unadjusted } & \multicolumn{2}{|l|}{ Adjusted $^{a}$} \\
\hline & & HR $(95 \% \mathrm{Cl})$ & $p$ Value & HR $(95 \% \mathrm{Cl})$ & $p$ Value \\
\hline MMF- & $11(44.0)$ & 1 (Reference) & NA & 1 (Reference) & NA \\
\hline MMF+ & $4(7.4)$ & $0.14(0.05-0.45)$ & 0.001 & $0.08(0.02-0.28)$ & $<0.001$ \\
\hline
\end{tabular}

Abbreviations: HR = hazard ratio; MMF: mycophenolate mofetil; MOG = myelin oligodendrocyte glycoprotein; NA: not applicable.

adjusted for age type at index date, sex, disease course, and initial level of MOG-IgG titer.

In our study, nearly half of the patients not receiving MMF suffered relapse, similar to previous reports $(36 \%-60 \%) .^{9,10}$ However, patients who were under MMF therapy showed a much lower relapse rate than those reported by other studies, such as $22 \%-26 \%$ in the $\mathrm{UK}^{10}{ }^{10} 20 \%$ in France, ${ }^{24}$ $42.1 \%$ in China, ${ }^{22}$ and $53.5 \%$ in the United States, ${ }^{20}$ with median follow-up times of 16 months, 2, 2.3 , and 5 years, respectively, probably because of the differences between the studies in treatment regimens and the concomitant use of oral prednisone. ${ }^{20}$ However, prednisone alone was unable to lower the relapse risk in our study. The time from index onset to relapse was similar to that in the previous studies (5-9 months). ${ }^{2,9}$ Although a UK study reports that patients younger than 20 years or with pure optic neuritis show a tendency to relapse, ${ }^{10}$ relapse risk in our study was not influenced by age type or first onset type.

Jurynczyk et al. ${ }^{10}$ found that prednisone tapering more than 6 months was able to reduce the relapse rate. In our study, the duration and dosage of prednisone before index date were heterogenous and unregular, which was a possible bias to our results. However, there were no differences in the dosage and durations of prednisone between 2 groups after index date, as were its usage rate before index date.

The serum titer of MOG-IgG is associated with age, onset type, therapy in the acute phase, and disease activity and also predicts prognosis. ${ }^{3,25,26}$ The negative transformation of antibody predicts good prognosis, ${ }^{2}$ whereas high titers predict a recurrent disease course. ${ }^{27}$ All possible confounders in our study were comparable between high and low MOG-IgG titer groups. We speculate that the titer is reflective of disease activity. Different from previous reports, ${ }^{2,27}$ the titer level was not associated with the relapse risk. However, the effect of MMF seemed more pronounced in patients with a high initial titer, although this requires further studies for confirmation. In addition, we noticed that the transient seropositivity of MOG-IgG rarely experienced relapse ${ }^{2}$; the negative transformation rate in the MMF- group was higher than that in the MMF+ group ( $24.0 \%$ vs $16.7 \%$ ), which probably underestimate the effect of MMF in our study.

Hacohen et al. $^{20}$ found that children with relapsing MOGAD were refractory to interferon-beta and glatiramer but responsive to MMF, AZA, rituximab, and oral prednisolone, with a significant reduction in ARR. Our study confirmed that a relapsing course at the index date was not associated with subsequent relapse risk, and MMF showed a consistent effect across the subgroups with different ARRs. In addition, patients with both long and short disease durations responded well to MMF, which has not been previously reported. ${ }^{9,20}$

Our study confirms the efficacy of MMF reported by previous retrospective studies with small numbers of patients ${ }^{20,24}$ and shows that MMF therapy was the only predictor of relapse. Standard treatment with prednisolone not only reduces relapse risk ${ }^{10,20}$ but also limits the risk of MMF failure. ${ }^{24}$ Furthermore, we found that patients with pure optic neuritis, prodromal infection, or a higher MOG-IgG titer seemed more responsive to MMF, which have not been reported. However, our study could not demonstrate that MMF is superior to other immunosuppressants. For instance, AZA and rituximab are still reasonable choices. ${ }^{9,10,20}$ Although more than 3 months of immunosuppression therapy is associated with a lower relapse risk, ${ }^{10}$ the underlying mechanism and the proper timing of immunosuppressant cessation remain inconclusive. ${ }^{23,28,29}$ Further studies on the role of B cells and its pathology during MMF therapy possibly provided new clues to optimize the MMF regimen. ${ }^{30}$

The EDSS of both groups were lower than that in other studies. ${ }^{9,10}$ We speculate 2 reasons: (1) Chinese might respond well to immunosuppressants, as another study in China showed lower EDSS than that in the non-Chinese cohort $^{9,10,22}$; and (2) our study had shorter follow-up times than other studies, ${ }^{9,10}$ which might have less relapses.

In analysis, all our patients were examined using the diagnostic criteria for MOGAD proposed by Pittock et al. ${ }^{2}$ and Jarius et al., ${ }^{8}$ and all met the above 2 diagnostic criteria. Therefore, the results of our study are not restricted to our cohort but may be generalizable to a larger population of patients with MOGAD.

Recently, Waters et al. ${ }^{31}$ reported that clinical specificity for IIFT and live assays is $98.1 \%$ and $99.6 \%-100 \%$, respectively, but both methods are internationally recommended. ${ }^{8}$ The positive predictive values of the commercial IIFT were lower than that of live assays, indicating a higher number of false positive results but was within an acceptable range. Because live assays are not economical or practical for routine 


\begin{tabular}{|c|c|c|c|c|c|c|}
\hline \multirow[b]{3}{*}{ Subgroup } & \multicolumn{6}{|c|}{ Patients with event/total: } \\
\hline & \multicolumn{2}{|c|}{ Patients, no. (\%) } & \multirow{2}{*}{$\begin{array}{l}\text { Hazard ratio } \\
(95 \% \mathrm{CI})\end{array}$} & \multirow{2}{*}{$\begin{array}{l}\text { Favors } \\
\text { MMF- }\end{array}$} & \multirow{2}{*}{$\begin{array}{l}\text { Favors } \\
\text { MMF+ }\end{array}$} & \multirow{2}{*}{$\begin{array}{l}p \text { value for } \\
\text { interaction }\end{array}$} \\
\hline & MMF- & MMF+ & & & & \\
\hline Overall & $11 / 25(44.0)$ & $4 / 54(7.4)$ & $0.14(0.05-0.45)$ & $\longmapsto-1$ & & \\
\hline \multicolumn{5}{|l|}{ Age group at first onset } & & 0.998 \\
\hline Children & $5 / 14(35.7)$ & $1 / 21(4.8)$ & $0.12(0.01-1.02)$ & $\longmapsto$ & & \\
\hline Adults & $6 / 11(54.5)$ & $3 / 33(9.1)$ & $0.13(0.03-0.51)$ & $\longmapsto$ & & \\
\hline \multicolumn{6}{|l|}{ Age group at index date } & 0.938 \\
\hline Children & $5 / 13(38.5)$ & $0 / 16(0.0)$ & $0.01(0.0-16.54)$ & $4=$ & & \\
\hline Adults & $6 / 12(50.0)$ & $4 / 38(10.5)$ & $0.17(0.05-0.60)$ & $\longmapsto$ & & \\
\hline \multicolumn{6}{|l|}{ Sex } & 0.684 \\
\hline Male & $5 / 9(55.6)$ & $3 / 23(13.0)$ & $0.16(0.04-0.67)$ & $\longmapsto$ & & \\
\hline Female & $6 / 16(37.5)$ & $1 / 31(3.2)$ & $0.09(0.01-0.72)$ & $\longmapsto$ & & \\
\hline \multicolumn{6}{|l|}{ Prodrome to first onset ${ }^{a}$} & 0.390 \\
\hline None & $2 / 5(40.0)$ & $2 / 16(12.5)$ & $0.25(0.04-1.81)$ & - & $\dashv$ & \\
\hline Preceding infection/vaccination & $7 / 18(38.9)$ & $1 / 30(3.3)$ & $0.08(0.01-0.67)$ & $\longmapsto$ & & \\
\hline Other & $2 / 2(100.0)$ & $1 / 8(12.5)$ & - & & & \\
\hline \multicolumn{5}{|l|}{ First onset type ${ }^{b}$} & & 0.920 \\
\hline Pure optic neuritis & $5 / 9(55.6)$ & $2 / 19(10.5)$ & $0.15(0.03-0.75)$ & $\longmapsto$ & & \\
\hline Pure cerebral involvement & $3 / 8(37.5)$ & $0 / 16(0.0)$ & $0.01(0.0-240.35)$ & $4=$ & & \\
\hline Pure spinal involvement & $0 / 1(0.0)$ & $0 / 4(0.0)$ & - & & & \\
\hline Other & $3 / 7(42.9)$ & 2/15 (13.3) & $0.31(0.05-1.87)$ & - & 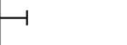 & \\
\hline \multicolumn{6}{|l|}{ Disease course } & 0.920 \\
\hline First onset & $3 / 9(33.3)$ & $0 / 13(0.0)$ & $0.01(0.0-144.02)$ & $4=$ & & \\
\hline Nonfirst onset & $8 / 16(50.0)$ & $4 / 41(9.8)$ & $0.16(0.05-0.53)$ & -1 & & \\
\hline \multicolumn{6}{|l|}{ ARR before index date ${ }^{c}$} & 0.881 \\
\hline 0 & $3 / 9(33.3)$ & $0 / 13(0.0)$ & $0.01(0.0-144.02)$ & $4-$ & & \\
\hline$<3.0$ & $4 / 7(57.1)$ & $3 / 28(10.7)$ & $0.12(0.03-0.54)$ & $\longmapsto$ & & \\
\hline$\geq 3.0$ & $4 / 9(44.4)$ & $1 / 13(7.7)$ & $0.21(0.02-1.89)$ & $\longmapsto$ & 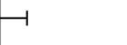 & \\
\hline \multicolumn{5}{|l|}{ Initial MOG-IgG titer ${ }^{d}$} & & 0.785 \\
\hline$<1: 100$ & $2 / 9(22.2)$ & $1 / 20(5.0)$ & $0.19(0.02-2.13)$ & $\longmapsto$ & $\longrightarrow$ & \\
\hline$\geq 1: 100$ & $9 / 15(60.0)$ & $3 / 33(9.1)$ & $0.13(0.03-0.47)$ & $\longmapsto$ & & \\
\hline \multicolumn{5}{|c|}{ Time from first onset to index date } & & 0.770 \\
\hline$<1,000$ days & $8 / 20(40.0)$ & $2 / 34(5.9)$ & $0.14(0.03-0.66)$ & $\longmapsto$ & & \\
\hline$\geq 1,000$ days & $3 / 5(60.0)$ & $2 / 20(10.0)$ & $0.10(0.02-0.62)$ & $\longmapsto$ & & \\
\hline
\end{tabular}

(A) Other includes 3 patients who were pregnant/lactating and 7 with fatigue/poor sleep/tension. (B) Other includes 9 with cerebellum/brain stem involvement, 4 with optic neuritis and cerebrum involvement, 3 with myelitis and cerebrum involvement, 2 with optic neuritis and myelitis, 2 with cerebellum/ brain stem and cerebrum involvement, and 2 with meningitis. (C) 0 : patients with 1 attack before the index date; $<3.0$ : patients with $\geq 2$ attacks before the index date and ARR <3.0; $\geq 3.0$ : patients with $\geq 2$ attacks before the index date and ARR $\geq 3.0$. (D) Two missing datapoints. ARR = annualized relapse rate; HR = hazard ratio; $\mathrm{MMF}=$ mycophenolate mofetil; $\mathrm{MOG}=$ myelin oligodendrocyte glycoprotein.

diagnosis, we used IIFT with a MOG antibody in this realworld clinical study.

The imbalance follow-up times is a bias that usually leads to spurious difference in relapse between the $\mathrm{MMF}+$ and MMF- groups. Theoretically, more relapse events were expected to observe in the MMF+ group, which had a longer median duration of follow-up. However, the observed data showed the opposite (11 relapse events for MMF- and 4 relapse events for $\mathrm{MMF}+$ ), which indicated that the follow-up time of the MMF+ group had negative association with relapse events in patients with MOGAD.

Our study had several limitations. First, it was an observational study, and its results could be biased by baseline patient characteristics, such as age. We were also unable to exclude 
a placebo effect. Second, the detection of associations between other confounders and relapse might have been limited by the relatively small number of patients. Thus, the results of subgroup analyses should be interpreted cautiously, and further studies with larger patient populations and longer follow-ups are needed. Third, we noticed that almost $90 \%$ of patients in the MMF+ group were using prednisone concomitantly, and we could not completely exclude the synergetic effect of prednisone on MMF, although standard therapy was given on both groups. Finally, considering the adverse effects of prednisone among children and teratogenicity of MMF in pregnant women, ${ }^{32,33}$ neurologists must balance its benefits and risks in clinical practice because the follow-up time in our study might not have been sufficient to detect all adverse effects.

Despite some limitations, this prospective observational study suggests that the use of MMF therapy may reduce the risk of relapse in patients with MOGAD. A future large randomized controlled trial with long-term follow-up is needed to evaluate the safety and efficacy of MMF in patients with MOGAD. It is also important to elucidate the mechanisms underlying the association between MMF and reduced relapse risk to optimize MMF therapy.

\section{Study funding}

This study was funded by the National Key Research and Development Program of China (Grant No. 2016YFC0901500), Peking Union Medical College Hospital Science Fund for Junior Faculty (pumch-2016-2.14), and Peking Union Medical College Education Reform Fund (2017zlgc0121).

\section{Disclosure}

S. Li, H. Ren, Y. Xu, T. Xu, Y. Zhang, H. Yin, W. Zhang, J. Li, X. Ren, F. Fang, W. Li, Y. Zhu, B. Peng, J. Wang, Y. Zhong, and L. Cui report no disclosures. Go to Neurology.org/NN for full disclosures.

\section{Publication history}

Received by Neurology: Neuroimmunology \& Neuroinflammation October 19, 2019. Accepted in final form February 5, 2020.

\section{Appendix Authors}

\begin{tabular}{lll}
\hline Name & Location & Contribution \\
\hline $\begin{array}{l}\text { Shengde } \\
\text { Li, MD }\end{array}$ & $\begin{array}{l}\text { Peking Union Medical } \\
\text { College Hospital, Beijing, } \\
\text { China }\end{array}$ & $\begin{array}{l}\text { Designed and conceptualized } \\
\text { the study; interpreted and } \\
\text { analyzed the data; drafted the } \\
\text { manuscript for intellectual } \\
\text { content. }\end{array}$ \\
\hline $\begin{array}{l}\text { Haitao } \\
\text { Ren, BS }\end{array}$ & $\begin{array}{l}\text { Peking Union Medical } \\
\text { College Hospital, Beijing, }\end{array}$ & $\begin{array}{l}\text { Major role in the acquisition of } \\
\text { data }\end{array}$ \\
\hline Yan Xu, \\
MD, PhD & $\begin{array}{l}\text { Peking Union Medical } \\
\text { College Hospital, Beijing, } \\
\text { China }\end{array}$ & $\begin{array}{l}\text { Designed and conceptualized } \\
\text { the study; interpreted and } \\
\text { analyzed the data; revised the } \\
\text { manuscript for intellectual }\end{array}$ \\
& $\begin{array}{l}\text { content. } \\
\end{array}$ &
\end{tabular}

\section{Appendix (continued)}

\begin{tabular}{|c|c|c|}
\hline Name & Location & Contribution \\
\hline $\begin{array}{l}\text { Tao Xu, } \\
\text { MD }\end{array}$ & $\begin{array}{l}\text { Peking Union Medical } \\
\text { College, Beijing, China }\end{array}$ & Analyzed the data \\
\hline $\begin{array}{l}\text { Yao } \\
\text { Zhang, } \\
\text { MD }\end{array}$ & $\begin{array}{l}\text { Peking Union Medical } \\
\text { College Hospital, Beijing, } \\
\text { China }\end{array}$ & $\begin{array}{l}\text { Major role in the acquisition of } \\
\text { data }\end{array}$ \\
\hline $\begin{array}{l}\text { Hexiang } \\
\text { Yin, MD }\end{array}$ & $\begin{array}{l}\text { Peking Union Medical } \\
\text { College Hospital, Beijing, } \\
\text { China }\end{array}$ & $\begin{array}{l}\text { Major role in the acquisition of } \\
\text { data }\end{array}$ \\
\hline $\begin{array}{l}\text { Weihua } \\
\text { Zhang, } \\
\text { MD }\end{array}$ & $\begin{array}{l}\text { Beijing Children's } \\
\text { Hospital, Beijing, China }\end{array}$ & $\begin{array}{l}\text { Major role in the acquisition of } \\
\text { data }\end{array}$ \\
\hline $\begin{array}{l}\text { Jiuwei Li, } \\
\text { MD }\end{array}$ & $\begin{array}{l}\text { Beijing Children's } \\
\text { Hospital, Beijing, China }\end{array}$ & $\begin{array}{l}\text { Major role in the acquisition of } \\
\text { data }\end{array}$ \\
\hline $\begin{array}{l}\text { Xiaotun } \\
\text { Ren, MD }\end{array}$ & $\begin{array}{l}\text { Beijing Children's } \\
\text { Hospital, Beijing, China }\end{array}$ & $\begin{array}{l}\text { Major role in the acquisition of } \\
\text { data }\end{array}$ \\
\hline $\begin{array}{l}\text { Fang } \\
\text { Fang, } \\
\text { MD }\end{array}$ & $\begin{array}{l}\text { Beijing Children's } \\
\text { Hospital, Beijing, China }\end{array}$ & $\begin{array}{l}\text { Major role in the acquisition of } \\
\text { data }\end{array}$ \\
\hline $\begin{array}{l}\text { Wenhan } \\
\text { Li, MD }\end{array}$ & $\begin{array}{l}\text { Oumeng V Medical } \\
\text { Laboratory, Hangzhou, } \\
\text { China }\end{array}$ & $\begin{array}{l}\text { Major role in the acquisition of } \\
\text { data }\end{array}$ \\
\hline $\begin{array}{l}\text { Yicheng } \\
\text { Zhu, MD }\end{array}$ & $\begin{array}{l}\text { Peking Union Medical } \\
\text { College Hospital, Beijing, } \\
\text { China }\end{array}$ & $\begin{array}{l}\text { Revised the manuscript for } \\
\text { intellectual content }\end{array}$ \\
\hline $\begin{array}{l}\text { Bin } \\
\text { Peng, } \\
\text { MD }\end{array}$ & $\begin{array}{l}\text { Peking Union Medical } \\
\text { College Hospital, Beijing, } \\
\text { China }\end{array}$ & $\begin{array}{l}\text { Revised the manuscript for } \\
\text { intellectual content }\end{array}$ \\
\hline $\begin{array}{l}\text { Jing } \\
\text { Wang, } \\
\text { MD }\end{array}$ & $\begin{array}{l}\text { University of Chinese } \\
\text { Academy of Sciences, } \\
\text { Beijing, China }\end{array}$ & $\begin{array}{l}\text { Revised the manuscript for } \\
\text { intellectual content }\end{array}$ \\
\hline $\begin{array}{l}\text { Yong } \\
\text { Zhong, } \\
\text { MD }\end{array}$ & $\begin{array}{l}\text { Peking Union Medical } \\
\text { College Hospital, Beijing, } \\
\text { China }\end{array}$ & $\begin{array}{l}\text { Major role in the acquisition of } \\
\text { data }\end{array}$ \\
\hline $\begin{array}{l}\text { Liying } \\
\text { Cui, MD }\end{array}$ & $\begin{array}{l}\text { Peking Union Medical } \\
\text { College Hospital, Beijing, } \\
\text { China }\end{array}$ & $\begin{array}{l}\text { Revised the manuscript for } \\
\text { intellectual content }\end{array}$ \\
\hline
\end{tabular}

\section{References}

1. Berg CT, Khorooshi R, Asgari N, Owens T. Influence of type I IFN signaling on antiMOG antibody-mediated demyelination. J Neuroinflammation 2017;14:127.

2. Lopez-Chiriboga AS, Majed M, Fryer J, et al. Association of MOG-IgG serostatus with relapse after acute disseminated encephalomyelitis and proposed diagnostic criteria for MOG-IgG-associated disorders. JAMA Neurol 2018;75:1355-1363.

3. Reindl M, Di Pauli F, Rostasy K, Berger T. The spectrum of MOG autoantibodyassociated demyelinating diseases. Nat Rev Neurol 2013;9:455-461.

4. Waters P, Woodhall M, O'Connor KC, et al. MOG cell-based assay detects non-MS patients with inflammatory neurologic disease. Neurol Neuroimmunol Neuroinflamm 2015;2:e89. doi: 10.1212/NXI.0000000000000089.

5. Sato DK, Callegaro D, Lana-Peixoto MA, et al. Distinction between MOG antibodypositive and AQP4 antibody-positive NMO spectrum disorders. Neurology 2014;82: 474-481.

6. Dubey D, Pittock SJ, Krecke KN, et al. Clinical, radiologic, and prognostic features of myelitis associated with myelin oligodendrocyte glycoprotein autoantibody. JAMA Neurol 2019;76:301-309.

7. Zhou L, Huang Y, $\mathrm{Li} \mathrm{H}$, et al. MOG-antibody associated demyelinating disease of the CNS: a clinical and pathological study in Chinese Han patients. J Neuroimmunol 2017;305:19-28.

8. Jarius S, Paul F, Aktas O, et al. MOG encephalomyelitis: international recommendations on diagnosis and antibody testing. J Neuroinflammation 2018;15:134.

9. Jarius S, Ruprecht K, Kleiter I, et al. MOG-IgG in NMO and related disorders: a multicenter study of 50 patients. Part 2: epidemiology, clinical presentation, radiological and laboratory features, treatment responses, and long-term outcome. J Neuroinflammation 2016;13:280. 
10. Jurynczyk M, Messina S, Woodhall MR, et al. Clinical presentation and prognosis in MOG-antibody disease: a UK study. Brain 2017;140:3128-3138.

11. Huh SY, Kim SH, Hyun JW, et al. Mycophenolate mofetil in the treatment of neuromyelitis optica spectrum disorder. JAMA Neurol 2014;71:1372-1378.

12. Xu Y, Wang Q, Ren HT, et al. Comparison of efficacy and tolerability of azathioprine, mycophenolate mofetil, and cyclophosphamide among patients with neuromyelitis optica spectrum disorder: a prospective cohort study. J Neurol Sci 2016; 370:224-228.

13. Fan $\mathrm{S}, \mathrm{Xu} \mathrm{Y}$, Ren $\mathrm{H}$, et al. Comparison of myelin oligodendrocyte glycoprotein (MOG)-antibody disease and AQP4-IgG-positive neuromyelitis optica spectrum disorder (NMOSD) when they co-exist with anti-NMDA (N-methyl-D-aspartate) receptor encephalitis. Mult Scler Relat Disord 2018;20:144-152.

14. Polman CH, Reingold SC, Banwell B, et al. Diagnostic criteria for multiple sclerosis: 2010 revisions to the McDonald criteria. Ann Neurol 2011;69:292-302.

15. Wingerchuk DM, Banwell B, Bennett JL, et al. International consensus diagnostic criteria for neuromyelitis optica spectrum disorders. Neurology 2015;85: 177-189.

16. Freedman LS. Tables of the number of patients required in clinical trials using the logrank test. Stat Med 1982;1:121-129.

17. Rosner B. Fundamentals of Biostatistics. 6th ed. Boston, MA: Duxbury Press; 2006.

18. Robins JM, Greenland S. The role of model selection in causal inference from nonexperimental data. Am J Epidemiol 1986;123:392-402.

19. Trebst C, Jarius S, Berthele A, et al; Neuromyelitis Optica Study Group (NEMOS). Update on the diagnosis and treatment of neuromyelitis optica: recommendations of the Neuromyelitis Optica Study Group (NEMOS). J Neurol 2014;261:1-16.

20. Hacohen Y, Wong YY, Lechner C, et al. Disease course and treatment responses in children with relapsing myelin oligodendrocyte glycoprotein antibody-associated disease. JAMA Neurol 2018;75:478-487.

21. Ramanathan S, Mohammad S, Tantsis E, et al. Clinical course, therapeutic responses and outcomes in relapsing MOG antibody-associated demyelination. J Neurol Neurosurg Psychiatry 2018;89:127-137.
22. Zhou J, Lu X, Zhang Y, et al. Follow-up study on Chinese children with relapsing MOG-IgGassociated central nervous system demyelination. Mult Scler Relat Disord 2019;28:4-10.

23. Hacohen Y, Banwell B. Treatment approaches for MOG-Ab-associated demyelination in children. Curr Treat Options Neurol 2019;21:2.

24. Montcuquet A, Collongues N, Papeix C, et al. Effectiveness of mycophenolate mofetil as first-line therapy in AQP4-IgG, MOG-IgG, and seronegative neuromyelitis optica spectrum disorders. Mult Scler 2017;23:1377-1384.

25. Jarius S, Ruprecht K, Kleiter I, et al. MOG-IgG in NMO and related disorders: a multicenter study of 50 patients. Part 1 : frequency, syndrome specificity, influence of disease activity, long-term course, association with AQP4-IgG, and origin. J Neuroinflammation 2016;13:279.

26. Song $\mathrm{H}$, Zhou H, Yang M, et al. Clinical characteristics and prognosis of myelin oligodendrocyte glycoprotein antibody-seropositive paediatric optic neuritis in China. Br J Ophthalmol 2019;103:831-836.

27. Hennes EM, Baumann M, Schanda K, et al. Prognostic relevance of MOG antibodies in children with an acquired demyelinating syndrome. Neurology 2017;89:900-908.

28. Choi SJ, Kim B, Lee HJ, Kim SJ, Kim SM, Sung JJ. Rebound of relapses after discontinuation of rituximab in a patient with MOG-IgG1 positive highly relapsing optic neuritis: a case report. BMC Neurol 2018;18:216.

29. Nagashima M, Osaka H, Ikeda T, et al. Rituximab was effective for acute disseminated encephalomyelitis followed by recurrent optic neuritis with anti-myelin oligodendrocyte glycoprotein antibodies. Brain Dev 2018;40:607-611.

30. Kothur K, Wienholt L, Tantsis EM, et al. B cell, Th17, and neutrophil related cerebrospinal fluid cytokine/chemokines are elevated in MOG antibody associated demyelination. PLoS One 2016;11:e0149411.

31. Waters PJ, Komorowski L, Woodhall M, et al. A multicenter comparison of MOG-IgG cell-based assays. Neurology 2019;92:e1250-e1255.

32. Aljebab F, Choonara I, Conroy S. Systematic review of the toxicity of long-course oral corticosteroids in children. PLoS One 2017;12:e170259.

33. Perez-Aytes A, Marin-Reina P, Boso V, Ledo A, Carey JC, Vento M. Mycophenolate mofetil embryopathy: a newly recognized teratogenic syndrome. Eur J Med Genet 2017;60:16-21. 


\section{Neurology \\ Neuroimmunology \& Neuroinflammation}

Long-term efficacy of mycophenolate mofetil in myelin oligodendrocyte glycoprotein antibody-associated disorders: A prospective study

Shengde Li, Haitao Ren, Yan Xu, et al.

Neurol Neuroimmunol Neuroinflamm 2020;7;

DOI 10.1212/NXI.0000000000000705

This information is current as of March 13, 2020

Neurol Neuroimmunol Neuroinflamm is an official journal of the American Academy of Neurology.

Published since April 2014, it is an open-access, online-only, continuous publication journal. Copyright

Copyright $\odot 2020$ The Author(s). Published by Wolters Kluwer Health, Inc. on behalf of the American

Academy of Neurology.. All rights reserved. Online ISSN: 2332-7812.

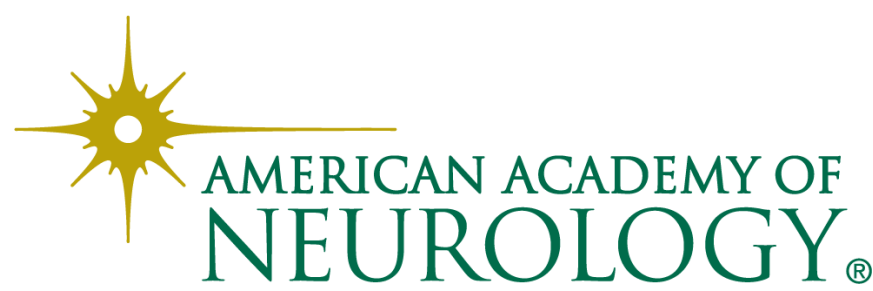




\section{Updated Information \& Services}

References

Citations

Subspecialty Collections

Permissions \& Licensing

Reprints including high resolution figures, can be found at: http://nn.neurology.org/content/7/3/e705.full.html

This article cites 32 articles, 3 of which you can access for free at: http://nn.neurology.org/content/7/3/e705.full.html\#\#ref-list-1

This article has been cited by 3 HighWire-hosted articles: http://nn.neurology.org/content/7/3/e705.full.html\#\#otherarticles

This article, along with others on similar topics, appears in the following collection(s):

All Demyelinating disease (CNS)

http://nn.neurology.org//cgi/collection/all_demyelinating_disease_cns All Immunology

http://nn.neurology.org//cgi/collection/all_immunology

All Spinal Cord

http://nn.neurology.org//cgi/collection/all_spinal_cord

Optic nerve

http://nn.neurology.org//cgi/collection/optic_nerve

Prognosis

http://nn.neurology.org//cgi/collection/prognosis

Information about reproducing this article in parts (figures,tables) or in its entirety can be found online at:

http://nn.neurology.org/misc/about.xhtml\#permissions

Information about ordering reprints can be found online:

http://nn.neurology.org/misc/addir.xhtml\#reprintsus

Neurol Neuroimmunol Neuroinflamm is an official journal of the American Academy of Neurology.

Published since April 2014, it is an open-access, online-only, continuous publication journal. Copyright

Copyright $\odot 2020$ The Author(s). Published by Wolters Kluwer Health, Inc. on behalf of the American

Academy of Neurology.. All rights reserved. Online ISSN: 2332-7812.

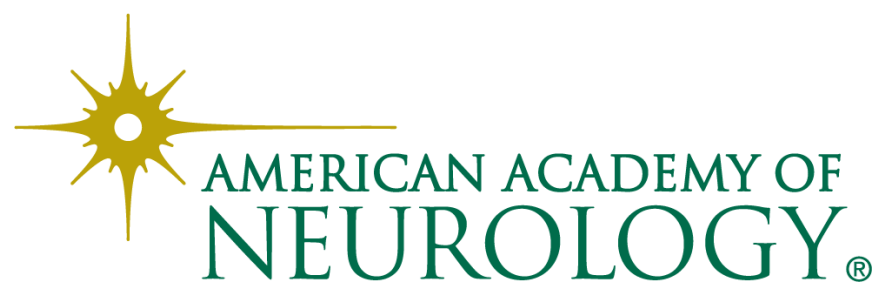

